\title{
Tiger Rag na interpretação do Le Quintette du Hot Club de France: história, análise e práticas de performance
}

\author{
Adriana Costa (Orquestra Opus, Belo Horizonte, MG) \\ costa33@terra.com.br
}

\begin{abstract}
Resumo: Estudo sobre a assimilação do jazz na cultura popular francesa dos anos de 1930 e criação de uma sociedade de entusiastas desse estilo, especialmente em torno do Le Quintette du Hot Club de France. A transcrição e análise de Tiger Rag, música dos membros da Original Dixieland Jazz Band (Nick La Rocca, Eddie Edwards, Tony Sbarbaro, Larry Shields e Harry da Costa) na interpretação do Le Quintette (LE QUINTETTE DU HOT CLUB DE FRANCE, 1934, remasterizado em 1993) revela suas práticas de performance, especialmente de seus solistas: Django Reinhardt, no violão, e Stephane Grappelli, no violino.

Palavras-chave: Django Reinhardt; Stephane Grappelli; jazz na França, Le Quintette du Hot Club de France.
\end{abstract}

Tiger Rag as performed by the Quintet of the Hot Club of France: history, analysis and performance practices

Abstract: Study about the assimilation of jazz into French popular culture of the 1930s and the emergence of a society of jazz enthusiasts, especially around Le Quintette du Hot Club de France. The transcription and analysis of Tiger Rag, composed by the members of the Original Dixieland Jazz Band (Nick La Rocca, Eddie Edwards, Tony Sbarbaro, Larry Shields and Harry da Costa) and performed by Le Quintette reveal performance practices of its main soloists: Django Reinhardt on the guitar and Stephane Grappelli on the violin.

Keywords: Django Reinhardt; Stephane Grappelli; jazz in France, Le Quintette du Hot Club de France.

\section{1 - As origens do Le Quintette du Hot Club de France}

Depois de alguns anos de exposição ao jazz, os músicos franceses começaram a formar suas próprias bandas no final dos anos 1920. No começo, os esforços desses pioneiros eram tênues em comparação com as bandas norteamericanas. Entretanto, no começo dos anos 1930, a França se tornou um dos primeiros paises europeus a produzir um grupo de músicos de jazz de reconhecida competência internacional. Para elevar o nível de compreensão e apreciação do jazz na França, Hughes Panassie, um entusiasta do jazz, criou e presidiu uma associação: o Hot Club de France (daqui para frente chamado apenas de Hot Club). 0 resultado mais importante do clube, entretanto, foi a formação de uma banda oficial para representar a organização: Le Quintette du Hot Club de France (daqui para frente chamado apenas de Le Quintette).
Desde a sua formação em 1932, os diretores do Hot Club planejavam formar uma orquestra para enfatizar o valor do então chamado "hot" jazz. 0 pianista negro norteamericano Freddy Johnson liderou a primeira orchestra do Hot Club, a qual ele chamou de Os Harlemitas. Johnson foi à França pela primeira vez em uma turnê com a orquestra de Sam Wooding em 1928; em 1929, ele fixou residência na França e formou sua própria banda. Os Harlemitas eram formados por Arthur Briggs no trompete, "Big Boy" Goodie no sax tenor, Peter Duconge na clarineta, Marceo Jefferson na guitarra, Juan Fernandez no baixo, e Billy Taylor na bateria (DELAUNAY, 1985, p.64).

Segundo Laurie Henshaw, que escrevia para a revista britânica Melody Maker, Os Harlemitas "tocavam sucessos musicais com muito swing, sob a batuta de Freddy Jonhson" (HENSHAW, 1942, p.4; todas as traduções são da 
autora do presente artigo). Embora obtendo um sucesso considerável, Johnson deixou a França em 1934 para tocar na Holanda. Sentindo que a falta de uma banda oficial poderia diminuir o interesse do público pelo jazz, o secretário do Hot Club, Pierre Nourry, foi procurar um substituto a altura de Os Harlemitas.

Na época em que Johnson foi embora de Paris, havia muitos outros músicos norte-americanos de jazz tocando nos clubes e cabarés de Paris que poderiam assumir o papel de promover o hot jazz. A banda de Willie Lewis tocava no Florence na Rue de Blance; a banda do trompetista Harry Cooper tocava no Ponto 2 todo sábado à tarde e tinha exelentes músicos como o clarinetista Jerry Blake e o saxofonista Booker Pitman. No começo do verão de 1934, o presidente honorário do Hot Club, Louis Armstrong, passou 18 meses em Paris, onde fez dois concertos na Salle Pleyel em novembro daquele ano. De acordo com o crítico e empresário de jazz francês Charles Delaunay, o Hot Club não tinha condições financeiras de contratar Armstrong, mas sua presença em Paris foi uma inspiração para os músicos parisienses. Portanto, até 1934, o Hot Club ainda não tinha uma banda oficial.

Apesar do grande número de músicos norte-americanos de jazz em Paris, os dirigentes do Hot Club sentiam a necessidade de ter "uma banda apenas com músicos franceses" (KENNEY, 1984, p.19). Acima de tudo, eles esperavam quebrar o mito vigente de que apenas os negros norte-americanos sabiam tocar jazz. No começo dos anos 1930, a ideia de "jazz francês" ainda era recebida com ceticismo. 0 musicólogo francês Blaise Pesquinne afirmou que, "não apenas é impossivel para um francês escrever um bom jazz, mas, mesmo que conseguisse, não haveria ninguém para tocar" (JORDAN, 1934, p.280). Em 1933, entretanto, o jazz francês já apresentava um movimento de expansão que permitia outras interferências, como pode ser exemplificado pela iniciativa do Hot Club que começou a misturar músicos franceses a norte-americanos nos seus concertos.

Em 10 de novembro de 1933, dois jovens músicos tocaram pela primeira vez no Hot Club: Noel Chiboust no trompete e Alix Combelle no saxofone (DELAUNAY, 1985, p.66). Em fevereiro do ano seguinte, o violonista Django Reinhardt, então com 24 anos, também se apresentou pela primeira vez. 0 crítico da revista Jazz Tango Jaques Bureau escreveu a respeito da performance de Reinhardt, "pode-se dizer que ele foi a revelação do concerto. Ele é um músico curioso com um estilo como nenhum outro" e concluiu "nós agora temos um grande improvisador em Paris" (DELAUNAY, 1985, p.64).

Enquanto os diretores do Hot Club procuravam por uma expressão francesa do jazz, ocorria também um mistura espontânea de músicos norte-americanos e franceses. A respeito de uma apresentação no Hot Club em março de 1934, a revista Jazz Tango observou: "Foi o fim do mundo quando Andre Ekyan, Jungo [sic.] Reinhardt, seu irmão e Al Romans se juntaram à Banda do 'Big Boy'. Foi um delírio encarnado, delírio que durou a noite toda" (DELAUNAY, 1985, p.64).

0 jovem Django Reinhardt se destacou dos seus contemporâneos franceses como um violonista que sabia improvisar. Nourry planejava começar uma banda com Reinhardt como líder, uma ideia que se tornou realidade quando o baixista Loius Vola formou uma banda para tocar na hora do chá no Hotel Claridge em Paris. Esta banda apresentava uma combinação de música popular e, ocasionalmente, jazz, onde tocavam os melhores músicos de jazz da França. A banda de Vola revezava com a orquestra de tango de Manuel Pizarro. Enquanto a orquestra de tango tocava, os músicos da banda de Vola passavam o tempo livre nos bastidores. Num desses intervalos, o violinista Stephane Grappelli foi trocar uma corda de seu violino e encontrou o violonista Django Reinhardt tocando. Grappelli se recorda que Reinhardt "me pediu para tocar uma frase que ele tinha acabado de inventar. 0 resultado nos agradou e nós continuamos tocando outras músicas" (GRAPPELLI, 1992, p.56). Dinah, uma canção popular dos anos de 1930 foi a primeira canção que eles tocaram juntos. No começo, eles tocavam para seu próprio divertimento, mas logo outros músicos começaram a notar a banda. Um dia, o irmão de Reinhardt, Joseph, se juntou ao duo fazendo o acompanhamento no violão e Vola se juntou a eles no contrabaixo. Os encontros diários no Hotel Claridge foram seguidos por ensaios à tarde no restaurante Alsace em Montmartre; o quarteto passou a causar sensação na pequena comunidade de jazz francesa.

A originalidade do grupo, tocando com instrumentos normalmente associados à música erudita, chamou a atenção de Pierre Nourry, o secretário do Hot Club. A principio, Nourry tinha a intenção de contratar o quarteto para acompanhar um jovem cantor francês, Raymond Valeda. Em setembro de 1934, Nourry, convidou Charles Delaunay para ouvir o quarteto e ter uma segunda opinião. Delaunay descreveu o que ele ouviu: "Lá em um canto, quatro homens tocavam uma música surpreendente pela sua veia melódica, pela delicadeza de sua improvisação, pela precisão de seu acompanhamento" (DELAUNAY, 1985, p.70). A banda impressionou Delaunay. Ele previu uma coisa única: a ideia de que "jazz sem trompetes ou bateria" agradaria ao público francês (SMITH, 1987, p.61). Ele entendeu que pessoas que não gostavam de jazz com trompetes, iriam gostar de jazz com instrumentos de cordas. Além disso, os instrumentos de cordas formam a base da música clássica europeia e estariam mais em sintonia com o gosto francês "do que o som dos instrumentos de metal das bandas norteamericanas" (KENNEY, 1984, p.20).

Atraidos pela ideia de um grupo só com instrumentos de cordas, a diretoria do Hot Club sugeriu uma gravação do grupo com a gravadora Odeon. Para este propósito, o quarteto adicionou uma terceira guitarra rítmica por sugestão 
de Reinhardt, que sentiu que deveria ter duas guitarras o acompanhando quando ele fazia os solos, assim como acontecia com Grapelli. Portanto, assim nasceu a combinação que se tornou a banda oficial do Hot Club. No final, Grappelli e Reinhardt eram os líderes do Le Quintette, com Joseph Reinhardt e Roger Chaput nas guitarras ritmicas e Louis Vola no contrabaixo. Embora este fosse o acordo inicial, logo no começo, Reinhardt já detinha o maior prestígio no meio jazzístico francês. Para melhor entender a singularidade do Le Quintette, vamos analisar sua música e compreender o desenvolvimento de suas figuras centrais.

\section{2- Django Reinhardt (1910-1953)}

Reinhardt era cigano e herdeiro de uma tradição musical que tinha como característica "a variedade rítmica, as síncopes, a música dançante, o virtuosismo, a paixão e a complexidade na improvisação" (KENNEY, 1984, p.17). Sua habilidade de construir um vocabulário musical vindo da tradição cigana, que incluía incriveis frases cromáticas, trilos, vibrato rápido, e aplicar estes efeitos ao jazz norte-americano, o tornou uma lenda do violão no jazz. 0 que também contribuiu para sua fama de Reinhardt foi o fato de que ele tocava passagens incrivelmente rápidas com apenas 2 dedos (indicador e médio) de sua mão direita. Isto se devia ao fato de que os outros 2 dedos (anular e mindinho) ficaram paralisados devido a queimaduras decorrentes de um incêndio no trailer onde ele morava, quando tinha 18 anos de idade. Reinhardt conseguia ocasionalmente tocar acordes usando os dedos paralisados.

Quando Reinhardt estourou na cena do jazz no final de 1934, seu impacto no desenvolvimento do violão como um instrumento solo no jazz foi inigualável. De 1928 até alguns meses antes de sua morte em 1953, Reinhardt gravou mais de 850 faixas, na maior parte jazz norteamericano, e também suas próprias composições. Até hoje, muitos o consideram como o único jazzman europeu a "ter dado à América um estilo instrumental novo tão influente quanto qualquer outro desenvolvido na pátria do jazz" (CHERRET, 2001, p.58). Este estilo teve muitos seguidores nos Estados Unidos e na Europa, e tornouse mais tarde conhecido como gypsy jazz (jazz cigano).

Os solos de Reinhardt cheios de lirismo e virtuosidade the valeram o título de gênio. "Um gênio no jazz," escreveu George Hoefer para a revista de jazz Down beat, é o instrumentista "que ao improvissar, o faz de uma forma tão genuína e inimitável, que foge de categorias pré-estabelecidas, como é o caso de Duke Ellington, Art Tatum e Django Reinhardt." (HOEFER, 1966, p.21). Ao longo de sua carreira, Reinhardt obteve uma imensa fama tanto na Europa quanto nos Estados Unidos, onde, em 1946, foi um convidado por Duke Ellington para uma turnê.

\section{3 - Stephane Grappelli (1908-1997)}

0 outro solista do Le Quintette teve a difícil tarefa de ser parceiro de um gênio. Por causa da fama de Reinhardt, alguns críticos não reconheceram inteiramente a contribuição de Grappelli para o quinteto, referindo-se a ele simplesmente como "o violinista de Django" (MORGENSTERN, 1967, p.18). A contribuição de Grappelli no desenvolvimento do Le Quintette, entretanto, não deve ser subestimada: ele era o principal arranjador do quinteto, além de ser o responsável pela transcrição das músicas, já que Reinhardt não sabia notação musical e tocava tudo de ouvido. Algumas das canções famosas do quinteto, como Minor Swing e Djangology foram escritas em parceria. Grappelli fornecia estabilidade, responsabilidade, e manteve 0 grupo operante mesmo durante as inúmeras ausências de Reinhardt, que muitas vezes preferia jogar cartas a cumprir seus compromissos com o Le Quintette. Além disso, como explica Alain Antonietto, "o sucesso do grupo era devido, sobretudo, à mistura perfeita de temperamentos musicais que eram completamente diferentes, antagônicos mesmo" (ANTONIETTO, 1990, p.12). 0 estilo de Grappelli, cheio da elegância e imaginação, complementava o senso rítmico e harmônico de Reinhardt. Junto com outros pioneiros como Joe Venuti e Stuff Smith, Grappelli deu um passo à frente, introduzindo o violino como um instrumento que poderia ser usado no jazz. Ele de fato se tornou uma lenda do violino no jazz. Grappelli, que foi o membro do Le Quintette com maior longevidade, morreu aos oitenta e nove anos, alguns meses após ter dado seu último concerto.

\section{4-Gravações do Le Quintette du Hot Club de France}

Durante sua existência entre 1934 e 1948, Le Quintette realizou 265 gravações. Destas, 125 foram feitas entre 1934 e 1939 e tiveram Grappelli ao violino. Em 1940, no início da Segunda Guerra Mundial, o quinteto estava em turnê na Inglaterra, onde era muito popular. Grappelli decidiu ficar na Inglaterra durante a guerra, enquanto que Reinhardt e os outros membros do grupo retornaram à França, ocasionando uma cisão na história do quinteto. De volta a Paris, Reinhardt continuou a tocar e gravar com diferentes grupos. Um ano mais tarde, ainda sem um co-lider, Reinhardt remontou o Le Quintette (mantendo o nome original), substituindo Grappelli pelo clarinetista Hubert Rostaing. Em vez de uma segunda guitarra ritmica, Reinhardt contratou o baterista Pierre Fouad. 0 Le Quintette com clarineta e bateria, "americanizado" em sua instrumentação, se tornou extremamente popular durante a ocupação nazista. Entre 1940 e 1943, o novo quinteto gravou pelo menos 27 faixas. Com o final da guerra, Grappelli retornou a Paris e o antigo quinteto foi reagrupado em 1946. De 1946 a 1948, o antigo quinteto (com Grappelli) e o novo (com o clarinetista Hubert Rostaing) gravaram pelo menos 105 faixas.

\section{5- Origem do ragtime}

0 rag ou ragtime é um gênero musical precursor do jazz, originado com os negros da região do meio-oeste norteamericano e que alcançou grande popularidade entre 0 final do século XIX e meados dos anos de 1930. Inicialmente idealizado para o piano, o ragtime absorveu influências de formas musicais europeias, em particular a marcha (SCHULLER, 1968, p.34). Assim como ocorre na marcha, a forma do ragtime é baseada em uma estrutura 
de 4 seções, (com versos para cada seção, no caso do ragtime cantado) sendo que o Trio, que ocorre na terceira seção, geralmente há uma modulação para a subdominante. Outras semelhanças entre as duas formas musicais são o andamento 2/4 ou 4/4 e, em muitos casos, a indicação Tempo de marcia, como no Maple Leaf Rag de Scott Joplin, um dos mais populares de todos os tempos.

Entre os compositores mais importantes de ragtime estão James Scott e Joseph Lamb, sendo que o primeirp ganhou maior notoriedade tanto nos Estados Unidos quanto no exterior, chegando a influenciar compositores eruditos como Eric Satie, Claude Debussy e Charles Ives, que também escreveram neste estilo (TIRRO, 1993, p.19). A História do Soldado de Igor Stravinsky de 1918 traz, entre os seus movimentos e ao lado de um Tango e uma Valsa, um Ragtime, refletindo três estilos musicais dançantes em voga no período da I Guerra Mundial (BORÉM, 2003).

Embora a forma do ragtime varie de uma composição para outra, a estrutura mais comum segue a seguinte sequência:

Introdução: 4 c.

Seção A: 16 c. com repetição

Seção B: 16 c. com repetição

Seção C ou Trio (modulação para a subdominante):

16 c. com repetição

Seção D: 16 c. com repetição

A harmonia empregada geralmente é convencional, baseada principalmente nas relações de tônica, dominante e subdominante. 0 ritmo geralmente se caracteriza por uma melodia sincopada que se apóia sobre uma linha não-sincopada no baixo (Ex.1).

\section{6-Considerações gerais sobre a transcrição de Tiger Rag}

Tiger Rag foi gravada pelo Le Quintette em 1934 e relançado diversas vezes. A transcrição que serviu de base para o presente artigo (ORIGINAL DIXIELAND JAZZ BAND, 2011, veja a partitura completa neste volume de Per Musi às p.89-92 foi feita a partir de uma remaste- rização de 1993 da Classics Records francesa (LE QUINTETTE DU HOT CLUB DE FRANCE, 1934, remasterizado em 1993). Nela, foi utilizado o sistema tradicional de notação com seus símbolos para dinâmica, fraseado, acentos e ataque. Entretanto, devemos lembrar, como Robert Witmer explica, que "a essência do jazz encontra-se precisamente nas características que a notação padrão não pode facilmente mostrar" (KERNFELD, 1988, p. 923). Portanto, elementos como sutilezas na afinação e ritmo são difíceis de representar no papel. Para fornecer uma representação mais aproximada das gravações, alguns sinais e símbolos foram acrescidos. Por exemplo, ghost notes ("notas fantasmas"), cuja articulação sutil e quase que apenas percussiva as tornam características, são representadas por um " $\mathrm{x"}$ "; os glissandi são notados com uma linha reta; o bend ("entortada"ou seja, ligeira caída na afinação seguida imediatamente por um retorno à nota original) é notado como um "v".

Tanto a Seção A quanto a Seção B têm oito compassos cada. Nesta transcrição, cada chorus (repetição completa da forma), que ocorre na seção D é mostrado pela barra dupla na partitura e pelo número da repetição. A numeração dos compassos de cada chorus é sempre de 1 a 32. Assim, a indicação chorus 2 - c.23-24, por exemplo, significa os compassos 23 a 24 do segundo chorus. $\mathrm{Na}$ discussão da transcrição, a oitava que vai do Dó central até o Si logo acima, será chamada de terceira oitava; assim, essas notas são designadas como Dó3 ao Si3; na oitava acima desta, são designadas como Dó 5 a Si 5, e assim por diante. Outros elementos que aparecem na forma em Tiger Rag são uma coda e um break (interrupção curta da música durante um solo por todos, incluindo a seção rítmica). 0 sistema de notação da harmonia utilizado é o de símbolos de acordes baseado no nome das notas em inglês começando pelo Lá: $A, B, C, D, E, F$ e G. Os acordes da transcrição anotados são os acordes ouvidos na gravação, embora os mesmos possam diferir dos acordes originais da canção. Todas as colcheias, a menos que seja indicado, soam como swing eights ("colcheias swingadas"), ou seja, duas colcheias seguidas soam como uma semínima seguida de colcheia em tercinas.

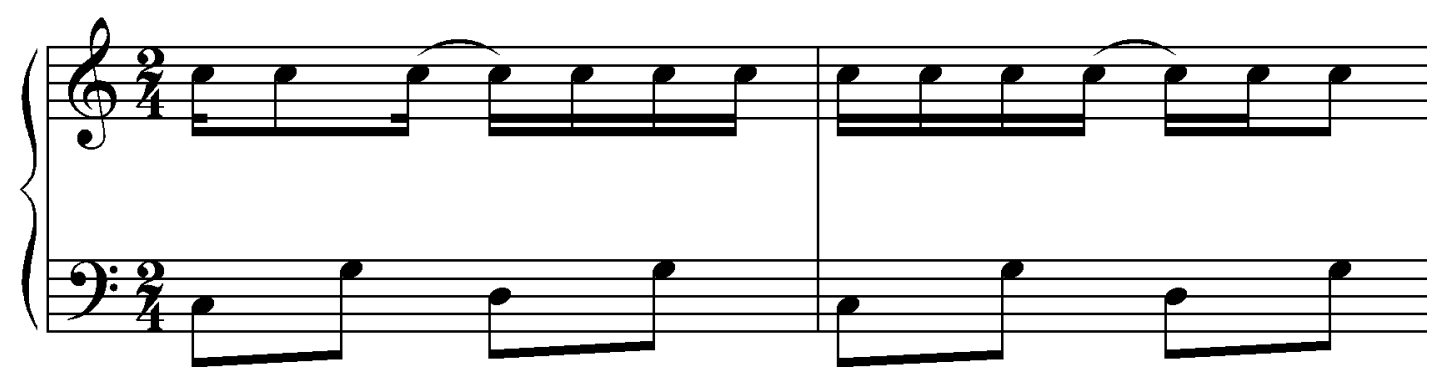

Ex.1 - Típico padrão de melodia sincopada sobre baixo não-sincopado do ragtime. 


\section{7 - Práticas de Performance em Tiger Rag}

Uma análise da transcrição da gravação de Tiger Rag (veja a edição de performance completa neste número de Per Musi) pelo selo Ultraphone (P-77162) revela bem o estilo do Le Quintette. Considerado um clássico do ragtime, Tiger Rag era tradicionalmente tocado em andamento rápido; nesta versão do quinteto 0 andamento é a semínima a 165. A forma e harmonia originais da música são as seguintes:

Seção A: 8 compassos repetidos em SibM

Seção B: 8 compassos em Fá M

Seção A: 8 compassos em SibM

Seção C (Trio): 24 compassos em MibM

Seção D: 32 compassos em LábM

A versão do Le Quintette manteve a forma original. $\mathrm{Na}$ Seção A, c.1-8, em Sib M, Reinhardt e Grappelli tocam sua versão do tema em sextas paralelas como podemos observar no (Ex.2).

Na Seção B, nos c.10-17, o violino toca o novo tema em Fá M. Após o retorno da Seção $A$, nos c.18-25, segue a Seção C , o trio, (c.26-49) em Mib M. Nesta seção, Grappelli toca uma frase diatônica descendente no c.26-27 que se distancia da melodia original, dando a ela um efeito blues, ao tocar a terça do acorde como terça menor (a nota Solb 5 , no c.26) e também a sétima como sétima menor (Réb 5, no c.27) sobre o acorde de Mib M (Ex.3).

Diferentemente do estilo de frases em legato de Grappelli, Reinhardt toca o próximo break de dois compassos (c.28-29) com ataques percussivos (Ex.4). Aqui, Reinhardt explora seguidamente o motivo formado por três semicolcheias cromáticas ascendentes, motivo que reflete uma técnica instrumental muito idiomática e comum no violão. Ao acentuar a primeira das três notas deste motivo, ele reforça a ideia de uma métrica ternária (3/8) dentro da rítmica binária prevalente (2/4), recurso que se tornou cada vez mais comum na improvisação do jazz. 0 break é finalizado por uma extensão do motivo cromático, cujo caráter conclusivo é enfatizado pela aceleração do mesmo por meio de fusas.

A Seção D em Lá b M é a seção dos solos de improvisação, composta de quatro choruses. Reinhardt começa sua improvisação no chorus 1 com uma anacruse de Lá $b$ (sobre um acorde de Mi b M) no compasso 49, antecipando a tônica do acorde seguinte. Mas, ao invés de confirmar esta tônica e de uma maneira incomum para a época, ele toca a sétima maior do acorde (a nota Sol 4), como mostra o Ex.5.

Com uma palheta, Reinhardt era capaz de tocar tremoli extremamente rápidos, como ocorre, por exemplo, no chorus 1 (c.21-24), uma habilidade provavelmente advinda da tradição cigana. Grappelli começa seu solo no chorus 2 tocando um motivo de duas notas, Mib 6 e Dó 6 (c.1-5). Ele varia as duas notas mudando seu ritmo cada vez que elas aparecem. No chorus 2 (c.23 e c.25), Grappelli toca notas blue: a sétima Dób 6 sobre 0 acorde de Db M. 0 chorus 3 começa com um solo do contrabaixo (c.1-14) de Louis Vola consistindo de frases escalares, mas o que segue, ao invés de uma continuação da improvisação, é um arranjo do grupo onde parte da melodia é executada pelo violino e, depois, pelo violão.
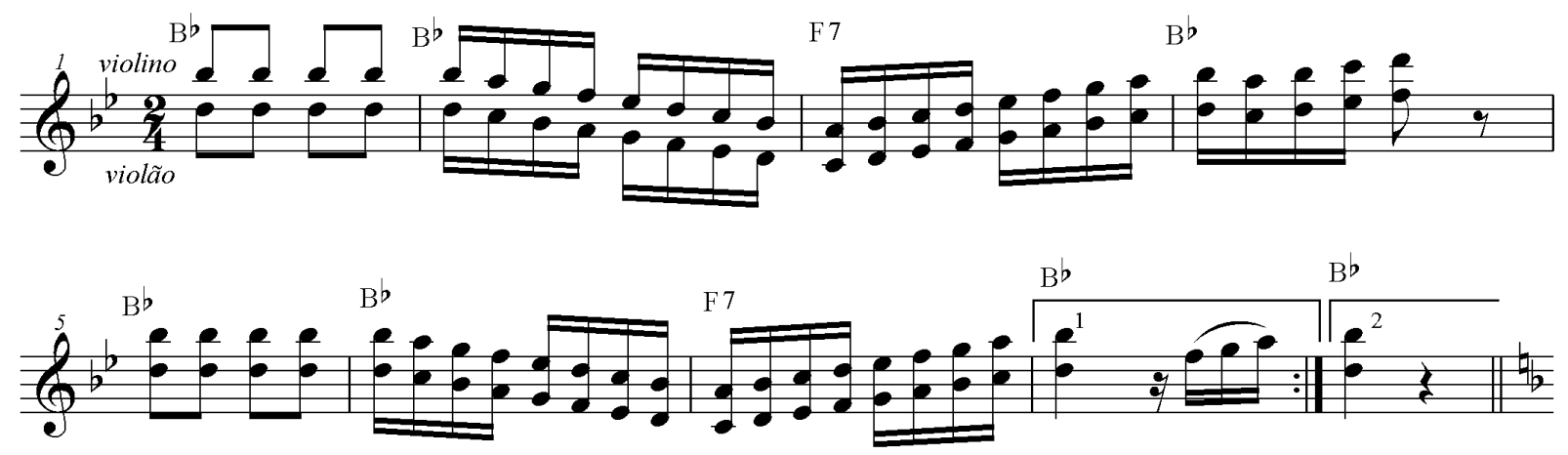

Ex.2 - Tema de Tiger Rag em sextas paralelas na performance de M, Reinhardt e S. Grappelli

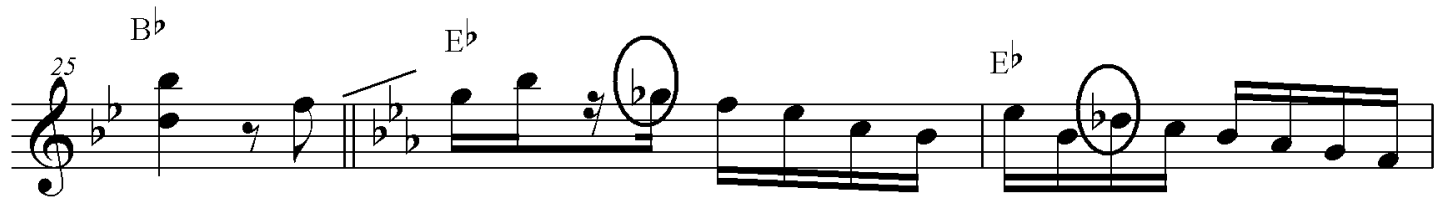

Ex.3 - Notas blue em improviso de S. Grappelli em Tiger Rag. 


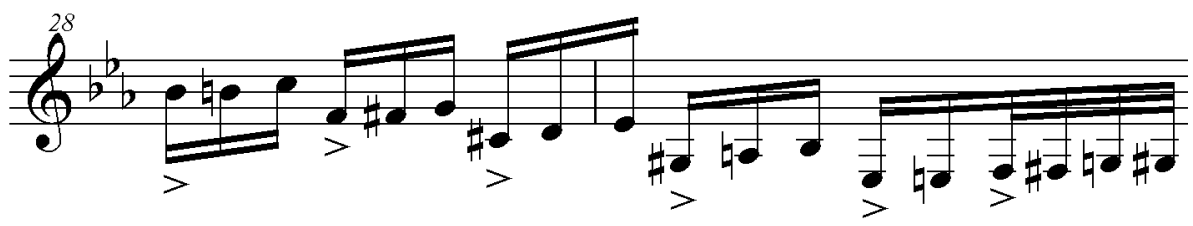

Ex.4 - Motivo cromático sugerindo métrica ternária na improvisação de D. Reinhardt na seção C de Tiger Rag.

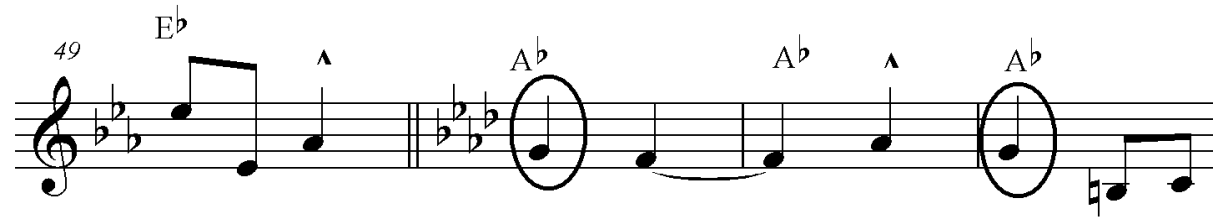

Ex.5 - Improvisação de D. Reinhardt em Tiger Rag com ênfase na sétima maior.

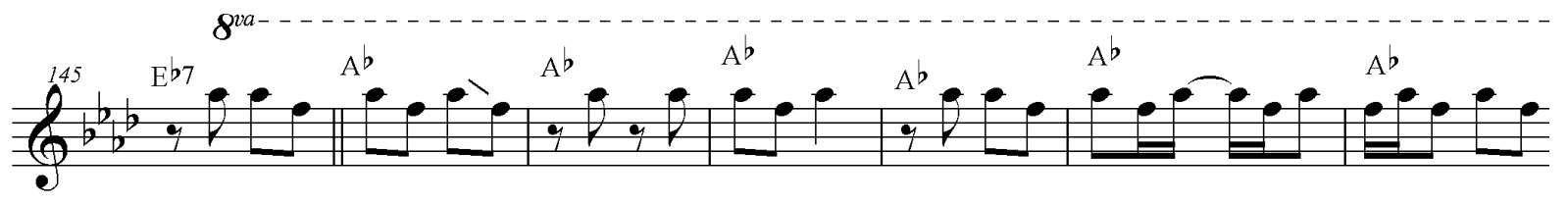

Ex.6 - Improvisação de S. Grappelli em Tiger Rag utilizando apenas duas notas.

Grappelli antecipa sua improvisação no chorus 4 (o último) de uma maneira parecida com o chorus 3 , isto é, alternando entre duas notas e variando seu ritmo, desta vez por sete compassos (c.145-151): o Láb 6 e o Fá 6, que são a tônica e a sexta do acorde de Láb M, respectivamente (Ex.6).

\section{8 - Considerações finais}

0 violonista Django Reinhardt e o violinista Stephane Grappelli lideraram, a partir de 1934 e por quase 15 anos, um dos melhores grupos de jazz que surgiram na Europa. No desejo de conciliar a música clássica com o jazz, a comunidade francesa interessada no gênero estimulou e apoiou a ascensão do Le Quintette du Hot Club de France. Nas big bands dos anos da década de 1930, a seção rítmica consistia principalmente de piano, guitarra, bateria, e baixo. Entretanto, a originalidade do Le Quintette, formado por um violino e um violão solistas, acompanhados por dois violões e um baixo, aliados ao virtuosismo e genialidade de Django Reinhardt e Stephane Grappelli, contribuiu para uma nova formação instrumental no jazz e ajudou a elevar o nivel de apreciação e de sua performance na França.

Até o começo dos anos de 1930, a maioria de músicos de jazz franceses imitava os jazzistas norte-americanos, o que é ilustrado na fala do musicólogo de jazz William KENNEY (1984, p.22):
Phillipe Brun chegou a tocar bem o trompete num estilo altamente influenciado por Bix Beiderbecke. No começo de sua carreira, Andre Ekyan soava bem parecido com Frank Trumbauer no saxofone do alto. 0 jovem Alix Combelle só pensava em Coleman Hawkins.

Entretanto, Reinhardt e, talvez com menos destaque, mas igualmente importante, Grappelli, se destacaram entre seus contemporâneos europeus, sendo os primeiros a desenvolver um estilo altamente pessoal dentro do jazz na Europa. Sua importância histórica ainda pode ser observada pelas constantes re-edições das gravações do Le Quintette, que parecem ter um público sempre renovado.

0 estilo de improvisação de Reinhardt e Grappelli pode ser verificado através de uma análise da transcrição de Tiger Rag, onde podemos também constatar a opinião comum, de que Reinhardt geralmente exibia uma improvisação mais sofisticada do que Grappelli.

Ainda nos dias de hoje, bandas que tocam no estilo do Le Quintette podem ser encontradas em locais referenciais como o Hot Club of San Francisco, Hot Club of Detroit, e outros lugares em todo o mundo, demonstrando que o gypsy jazz e as tradições do grupo Le Quintette du Hot Club de France continuam vivas. 


\section{Referências de texto}

ANTONIETTO, Alain. Djangology. Notas do CD.EMI France, v.1-11, 1990, p.12.

BORÉM, Fausto. 0 anticlímax da História do Soldado de Stravinsky: proporção, coerência harmônica e relação textomúsica na sequência Pequeno Coral, Canção do Diabo e Grande Coral. Em Pauta. v.12. Porto Alegre: UFRGS, 2003. p.131-154.

CHERRET, Ted, ed. The Genius that was Django Reinhardt. London: privately printed, 2001, p. 58.

DELAUNAY, Charles. Delaunay's Dilemma: De la Peinture au Jazz. Macon: Editions W, 1985, p.64.

GRAPPELLI, Stéphane avec Joseph Oldenhove, Jean Marc Bramy. Mon Violon pour tout Bagage: Mémoires. Paris: CalmannLévy, 1992, p. 56.

HENSHAW, Laurie. "Swing Guitars." Melody Maker Agosto 1942, p. 4.

HOEFER, George. "The Magnificent Gypsy." Down Beat 14 July 1966 : p. 21-24.

JORDAN, Matthew F. "Jazz Changes: A History of French Discourse on J Jazz from Ragtime to Be-Bop." Ph.D. Dissertation, Claremont Graduate School, 1998, p.281.

KENNEY, William Howland. "Le 'Hot:' the Assimilation of American Jazz in France, 1917-1940." American Studies 25 (Spring 1984): p. 5-24.

KERNFELD, Barry, ed., The New Grove Dictionary of Jazz London: Macmillan Press, 1988, p.932, s.v. "Notation" by Robert Witmer.

MORGENSTEN, Dan. "Jazz Fiddle." Downbeat 34 February, 1967, p.16-19.

SCHULLER, Gunther. Early Jazz. Oxford University Press: New York, 1968, p.34.

SMITH, Geoffrey. Stéphane Grappelli. London: Pavilion, 1987, p.61.

TIRRO, Frank. Jazz.: A History. W.W.Norton\&t Company: New York, 1993, p.19.

\section{Referência sonora}

LE QUINTETTE DU HOT CLUB DE FRANCE. Tiger Rag. In: Chronological Django Reinhardt: 1934-1935. Classics Records, França, remasterizado em 1993.

\section{Referência de partitura}

ORIGINAL DIXIELAND JAZZ BAND. Tiger Rag (1917) na performance do Le Quintette du Hot Club de France. Per Musi, Belo Horizonte, n.23, 2011, p.xxx-xxx.

Adriana Costa é Mestre em Música e Doutora em Música pela Shennadoah University (EUA), violinista da Orquestra de Câmera OPUS, pesquisadora e professora de violino. Tem trabalhos publicados na área do jazz pela International Association of Jazz Educators Journal e Nottingham Univesity Press. Além disso, já apresentou trabalhos de pesquisa na International Association of Jazz Educators Conference nos EUA e na Hot and Cool Conference em Seysses na França. 